\title{
EL ANTIGUO TRAPICHE DE MASCARILLA, LA MEMORIA DE LA ESCLAVITUD Y EL PATRIMONIO MATERIAL AFROECUATORIANO
}

\author{
THE OLD TRAPICHE OF MASCARILLA, THE MEMORY OF SLAVERY \\ AND AFROECUADORIAN MATERIAL HERITAGE
}

\author{
John Antón Sánchez*
}

\begin{abstract}
Este artículo es una síntesis del informe investigación de enfoque etnográfico y etnohistórico realizado en el 2012 para el Instituto Nacional de Patrimonio Cultural del Ecuador (INPC) respecto de la importancia del antiguo Trapiche de Mascarilla como bien patrimonial material de los afrodescendientes del Ecuador. El objetivo del estudio fue contar con un basamento técnico-científico, con perspectiva antropológica y de arqueología histórica, que fundamente el proyecto de rehabilitación y salvaguardia de este bien patrimonial para la construcción futura de un museo de la memoria de la Diáspora africana de las Américas en Ecuador.
\end{abstract}

Palabras claves: Afrodescendientes, arqueología histórica, etnografía, Ecuador, patrimonio material.

This article is a synthesis of the ethnographic and ethnohistorical research report carried out in 2012 for the National Institute of Cultural Heritage of Ecuador (INPC) on the importance of the Old Trapiche of Mascarilla as a patrimonial material of the Afrodescendants of Ecuador. The objective of the study was to have a technical-scientific basis, with an anthropological perspective and historical archeology, which founded the project of rehabilitation and safeguard of this heritage for the future construction of a museum of the memory of the African Diaspora of the Americas in Ecuador.

Key words: Afrodescendants, historical archeology, ethnography, Ecuador, material heritage.

\section{Introducción}

Este ensayo tiene por objetivo presentar la importancia que posee la actual ruina del Trapiche de la comunidad de Mascarilla en el inventario de bienes de la cultura material y patrimonial de los afrodescendientes del Ecuador. Contiene una adaptación a las conclusiones de un estudio de carácter etnohistórico y etnográfico acerca del tema realizado en el 2012 para el Instituto Nacional de Patrimonio Cultural del Ecuador, con el fin de responder a las demandas ciudadanas respecto de ¿cómo impulsar la rehabilitación del antiguo Trapiche de Mascarilla, para la memoria y resistencia de la esclavitud afrodescendiente?

En el 2011 el Instituto Nacional de Patrimonio Cultural (INPC) ejecutó una investigación de la religiosidad popular afrodescendiente en el norte de Esmeraldas y en el Valle del Chota. A partir de la indagación se detectó en la comunidad afroecuatoriana de Mascarilla (provincia del Carchi) la presencia de un inmueble de estructura colonial tardía conocido como "el antiguo trapiche", construcción que podría constituir un elemento de la cultura material asociado a la historia de la esclavitud africana en esta región del Ecuador. Fue entonces que el INPC decidió promover iniciativas con miras a la rehabilitación de esta edificación y a establecer relacionamientos en su contexto histórico, social y cultural.

El Trapiche de Mascarilla está en un predio cuya propiedad es de una asociación comunitaria de mujeres. La obra tiene una superficie aproximada de $2.000 \mathrm{~m}^{2}$ y estimada de $315 \mathrm{~m}^{2}$ de construcción (incluye un antiguo trapiche y la reciente edificación del Centro Juvenil de Mascarilla). Fue inventariado con Código No. BI-04-04-50-000-000002, protegido por la Ley de Patrimonio Cultural y su Reglamento.

De acuerdo con documentos oficiales del INPC, el "antiguo trapiche" evidencia lo que fue un establecimiento dedicado a la producción y procesamiento de caña en la zona y constituye una de las pocas edificaciones presentes en el Valle del Chota hechas de cal y canto, con galeras de piedra levantada en la época (tardía) de la Colonia. Por esta razón, las comunidades demandan su reconocimiento como un bien patrimonial cultural edificado que guarde la memoria de un pueblo sometido a la esclavitud.

* Instituto de Altos Estudios Nacionales (IAEN), Quito, Ecuador. Correo electrónico: john.anton@ iaen.edu.ec 


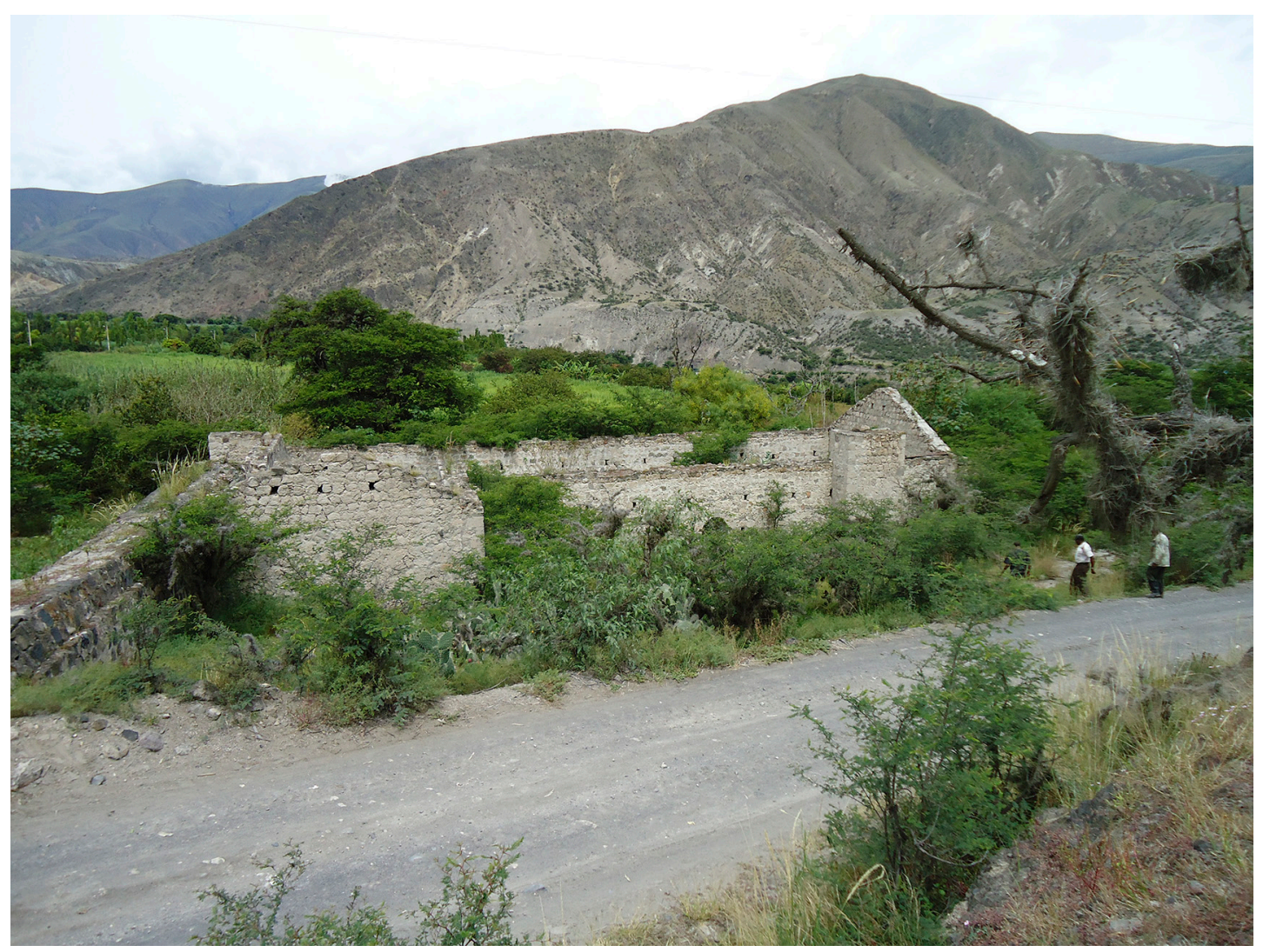

Fotografía 1. Vista del Trapiche de Mascarilla, valle del Chota (Ecuador). Autor John Antón.

Además, se trata de uno de los pocos lugares históricos que no están relacionados con aspectos de la religiosidad, la política, la institución militar o la vivienda señorial, objetos patrimoniales que han obtenido mayor grado de preservación.

La importancia de esta edificación demanda que se elaboren propuestas de intervención integral y coherente con su condición patrimonial, estas intervenciones deben valorar la situación actual y proponer acciones tendientes a la salvaguardia y a la rehabilitación del antiguo Trapiche de Mascarilla, con el fin de crear dispositivos culturales de la memoria en la resistencia a la esclavización por parte de los afrodescendientes. En consecuencia, por mandato del INPC se llevó a cabo un estudio de carácter etnográfico y etnohistórico del trapiche, con el fin de obtener una línea base para la propuesta de salvaguardia y nuevo uso del bien patrimonial.

Con base en lo anterior, se plantearon las siguientes preguntas de investigación: ¿constituye el Trapiche de Mascarilla un dispositivo de la memoria que debería revitalizarse para el fortalecimiento de la identidad cultural afroecuatoriana?, ¿cómo valoran las mismas comunidades la importancia de un bien material vinculado a su historia vivida durante los procesos de esclavitud?, ¿qué estrategias de carácter institucional y comunitario se deberían emprender para una eventual recuperación de dicho bien patrimonial?

El presente artículo recoge los resultados de una investigación cuyos logros concluyen que, en efecto, el Trapiche de Mascarilla representa para los afrodescendientes del Valle del Chota un importante inmueble cuyos componentes axiológicos, históricos y patrimoniales se relacionan con la historia de la esclavitud y constituyen un elemento consustancial de su identidad cultural.

El presente ensayo se divide en tres partes: la primera trata de la metodología con que se desarrolla el estudio, enfatizando las técnicas de las ciencias sociales, en especial de la antropología y la sociología, donde se privilegia el enfoque cualitativo y la recopilación de información documental, de la 
memoria oral y de la etnografía. La segunda parte contextualiza el lugar donde el trapiche se relaciona con la comunidad de Mascarilla, para ello se tienen en cuenta elementos descriptivos de la comunidad, datos de su historia y procesos organizativos que dan lugar a acciones colectivas y repertorios de acción que demandan por parte del Estado una estrategia de salvaguardia del patrimonio que representa este bien inmueble. La tercera parte presenta los resultados del trabajo de campo realizado a partir de datos etnohistóricos y etnográficos que han sido revelados desde la memoria oral de los actores comunitarios y que determinan lo que en realidad significa este trapiche para la identidad cultural afrodescendientes del Ecuador.

\section{Marco metodológico del estudio}

En el 2012 el Instituto Nacional de Patrimonio Cultural del Ecuador (INPC) solicitó una aproximación etnográfica y etnohistórica de la comunidad afroecuatoriana de Mascarilla y las ruinas de su trapiche de Caña, construido, al parecer, a mediados del siglo XIX. El objetivo fue conocer el estado de conservación del edificio, para proceder así a la configuración de una estrategia de salvaguardia, de acuerdo con las políticas de salvamento de los bienes patrimoniales del país.

El trabajo se realizó bajo la metodología de investigación antropológica, privilegiando un enfoque cualitativo, donde la información documental, la memoria oral y la etnografía fueron las herramientas principales. La antropología, entendida como disciplina de la cultura y como el campo que cuestiona la complejidad de la naturaleza humana (Rosaldo 1993), tiene su propio método: la etnografía, quizá la mayor contribución al desarrollo de las ciencias sociales (Adam Kupers 2000).

En este artículo, planteado como ejercicio etnográfico, e incluso desde un eventual interés por la arqueología histórica afrodescendiente, es importante problematizar la importancia patrimonial del Trapiche de Mascarilla: ¿cómo valora la comunidad el trapiche? para la resolución de esta y otras cuestiones, se propone la realización de observaciones y entrevistas a varias personas del lugar, entre ellas ancianos, jóvenes y mujeres, especialmente aquellas interesadas en la preservación de este lugar histórico.

La aplicación de procedimientos etnográficos respecto del trapiche destaca la importancia del modelo clásico ${ }^{1}$, aún vigente pese a las críticas, bien por poseer técnicas muy parecidas a los inicios de la antropología colonial como por su lenguaje sofisticado y muchas veces aburrido (Rosaldo 1997).

En relación con la existencia de alternativas para el desarrollo de etnografías menos acartonadas, Fontana (1994), desde una visión contemporánea, propone otras formas de hacer etnografías más flexibles en cuanto a las técnicas (posmodernas, multitextuales, feministas, nativas, etc.) y los lenguajes. Considerando la naturaleza del escenario de trabajo, quizá lo más apropiado para este estudio sea la perspectiva culturalista que defiende Clifford Geertz (1987), al plantearse la etnografía como una descripción densa. Esta opción se considera debido a que un trabajo antropológico no debería limitarse a describir el campo de las acciones sociales, establecer relaciones con los actores conocidos, o seleccionar textos y llevar diarios. Además de estas técnicas - por cierto muy pertinentes-, un estudio acerca de la vida social y cultural de los afrodescendientes y sus patrimonios debería explorar aspectos más allá de los imaginarios.

Con base en lo anterior, este estudio persigue una técnica antropológica que describa e inscriba, que lea textos y contextos, aquellos que se desprenden de esa urdimbre de significados que envuelven simbólica, espiritual e históricamente a la cultura afrodescendiente.

Ahora bien, la cuestión es cómo abordar metodológicamente el ejercicio etnográfico con las comunidades de Mascarilla, teniendo en cuenta que, de acuerdo con Taylor y Bogdan (1987), todo proceso etnográfico implica al menos tres actividades básicas: a) el ingreso al campo o la interacción social con los actores; b) la construcción de estrategias de campo para obtener la información y describir el fenómeno observado y; c) el registro y análisis de los datos, es decir, la interpretación.

Así descrita la metodología con que se abordará el objeto de estudio, a continuación se desarrolla el contexto del mismo, a partir de esto se precisarán, de igual manera, las herramientas metodológicas más notables para el análisis y el procesamiento de la información.

\section{Marco contextual: el patrimonio cultural afrodescendiente}

El patrimonio cultural material ${ }^{2}$ e inmaterial ${ }^{3}$, es considerado por la UNESCO como aquellos 
elementos de la cultura que requieren una adecuada atención, valoración y rescate, porque en ellos recaen continuas amenazas y desapariciones irremediables. Por ello, los estados nacionales deberían asumir la identificación, protección y conservación para las generaciones futuras del patrimonio cultural situado en su territorio. En Ecuador, la entidad responsable del cuidado y protección del patrimonio cultural es el INPC, creado mediante Decreto Supremo 2600 del 9 de junio de 1978 y publicado en el Registro Oficial No. 618 de 29 de junio de 1978.

La salvaguardia del patrimonio cultural material e inmaterial es importante toda vez que, en el contexto de la mundialización, muchas culturas son vulneradas por la imposición identitaria hegemónica eurocéntrica, los conflictos armados, el éxodo rural y las migraciones. Miguel Barnet (2006) considera que en el mundo contemporáneo "se comprueba los crecientes riesgos de extinción de la civilización" que se explicita en "la desaparición irreparable de idiomas y tradiciones, hasta la estandarización e imposición de modelos culturales a escala mundial" (Barnet 2006: 45). En Ecuador, durante el gobierno de Rafael Correa (2007-2017), la salvaguardia del patrimonio cultural fue una de las políticas que permitió contar con un registro detallado de los bienes patrimoniales de la nación.

Igual que el patrimonio cultural en general, se considera que el patrimonio cultural afrodescendiente debe ser tratado de manera integral, es decir, combinando los aspectos primordiales de su cultura material e inmaterial. Tanto el patrimonio material como el inmaterial son elementos intrínsecos de la cultura de los afrodescendientes. Estos se transmiten de generación en generación, y son recreados cotidianamente por sus comunidades y grupos sociales en función de su entorno, su interacción con la naturaleza y su historia. Dentro del patrimonio cultural, las comunidades afrodescendientes logran plasmar sus sentimientos de identidad y continuidad, contribuyendo así a promover el respeto de la diversidad cultural y la creatividad humana (CRIESPAL; UNESCO; CONACULTURA 2013).

Los estudios antropológicos e historiográficos respecto de la cultura afrodescendiente en América realizan esfuerzos para demostrar su carácter de originalidad más allá de los procesos de aculturación, enculturación y transculturación, como producto de la experiencia de hibridación de civilizaciones africanas, europeas y prehispánicas tejidas en lo que Paul Gilroy (2014) denominó el Atlántico Negro.
Autores clásicos como Merville Herskovitz (1941), Arthur Ramos (1937), Fernando Ortiz (1906) y Nina Rodríguez (1935), o incluso más recientes como Sidney Mintz y Richard Price (1976), José Franco Luciano (1975) y Manuel Moreno Fraginals (1977) hacen esfuerzos por interpretar las configuraciones identitarias determinadas por los afrodescendientes y sus comunidades en América Latina y el Caribe a partir de su experiencia de esclavización.

Etnólogos como Roger Bastide (1969) explican que los pueblos afrodescendientes devienen de un proceso de reconstrucción de las culturas africanas en las Américas, donde elementos como la música, la religiosidad, el lenguaje y la estética de los ancestros africanos, así como el deseo de libertad de los esclavizados, fueron la fundamentación de lo que hoy se denomina la diáspora africana en las Américas (M. Fraginals 1987). En este proceso también se encuentran aportes de culturas indígenas y de los colonizadores españoles (Zapata 1995). De este modo, la identidad cultural afrodescendiente fue alimentada por las relaciones de hibridación que se impusieron durante la Colonia, incluyendo el mismo mestizaje africano, dando como resultado un modelo cultural basado en la inculturación.

Cuando se trata de analizar los elementos del patrimonio cultural afrodescendiente, por lo general se hace referencia a aspectos inmateriales (Antón y Toaza 2013). Pocas veces se aprecia que poseen un rico repertorio de lugares de memoria enmarcados en monumentos, cementerios, plazas, centros culturales, bibliotecas, museos y otros objetos de la cultura material. Una de las propuestas para salvaguardar el patrimonio cultural material e inmaterial de los afroecuatorianos es la implementación de modelos de arqueología histórica en estas comunidades. Se trata de una disciplina que tiene su objeto situado en un espacio temporal propio del desarrollo civilizatorio de los afrodescendientes en las Américas: siglos XVI al XIX, cuando tuvo lugar la esclavización y fueron importados más de 15 millones de africanos al Nuevo Mundo (Antonio Saco 1933)

La arqueología histórica referencia modelos interpretativos, técnicas y metodologías que se han construido para estudiar las huellas del pasado más próximo (Montón y Abejez 2015). Su labor es la de obtener conocimiento de las sociedades que se formaron desde las dinámicas de contacto a partir del siglo XV en América. Lo "histórico" hace referencia a un principio de carácter metodológico que utiliza la documentación de los archivos de las 
épocas, con el fin de hacer referencia a los fenómenos sociales, políticos, económicos y culturales conformados desde el período colonial americano. La arqueología histórica centra sus procedimientos en descubrimientos, restauración y conservación de monumentos coloniales y republicanos como iglesias, colegios, cuarteles, fábricas, cárceles, guarniciones militares, cementerios, trapiches, haciendas, resguardos, fundaciones, campos de guerra, etc. (Hernández y Ramos 2011).

La arqueología histórica alcanza sustento en lo que hoy se denomina la Nueva Arqueología, un enfoque novedoso en las técnicas de excavaciones lideradas por el norteamericano Lewis Binford (1983) y que denominó New Arqueology, a una manera distinta de interpretar el dato arqueológico, a partir de referencias de tipo etnográfico y experimental. El modelo de la New Arqueology nos posibilita acercarnos al objeto de estudio mediante la técnica de comparación de los restos arqueológicos con las referencias actuales de la cultura material de los pueblos estudiados, cuyo soporte además parte del apoyo de ciencias auxiliares como la etnohistoria, la tradición oral, los archivos históricos y los recursos de sistematización de la museología.

En países como Colombia esta rama de la arqueología ha logrado un mediano desarrollo. Entre sus precursores figuran Luis Duque Gómez (1955), quien excavó el templo del sabio Mutis en la iglesia de Santa Inés en Bogotá; Grasciliano Arcila (1975-1977), quien exploró Santa María la Antigua del Darién; entre otros, como Miguel Méndez (1985) de la Universidad del Cauca y Mónica Therrien (1996).

Dicho lo anterior, es importante precisar unas notas que permitan -en un futuro- acercarnos a las ruinas del Trapiche de Mascarilla desde un modelo interpretativo de la arqueología histórica aplicado a comunidades afrodescendientes. A pesar de los progresos que la arqueología histórica ha logrado, esta disciplina aún no logra incidir a cabalidad en la cultura material de los afrodescendientes. Además de Estados Unidos, donde la disciplina ha tomado importancia en las últimas décadas, en América Latina existen avances en Cuba, Argentina, Brasil y Colombia ${ }^{4}$.

En el caso particular de Colombia, se han dado intentos por innovar en la arqueología histórica afrodescendiente desde los años noventa, cuando el lingüista norteamericano Armin Schwegler (1992, 1991), de la Universidad de California, realizó una excavación superficial en el palenque de San Basilio, a pocos kilómetros de Cartagena, siendo el primero en hablar de este tema. El autor realizó observaciones en el antiguo cementerio de Palenque, y anotó que, mediante la exploración sistemática de los restos arqueológicos, se pueden trazar inferencias respecto del origen bantú y subsahariano de los palenqueros (Suaza 1993).

Por su parte el antropólogo Francisco López (2002) investigó acerca de arqueología de haciendas en el Valle del Cauca, en especial la hacienda Cañas Gordas, donde se recrea la novela La María de Jorge Isaac. Se plantean así fundamentos para una arqueología especializada en comunidades afrodescendientes, un modelo de estudio que se propone la reconstrucción histórica del pueblo afrodescendiente a partir de su cultura material, teniendo en cuenta sus acervos culturales como la tradición oral, el mito, el arte, el folclore, además de los aportes de las fuentes primarias (Altez y Rivas 2015).

\section{El Trapiche de Mascarilla como patrimonio de la memoria histórica de la esclavización}

El trapiche que estudiamos en este artículo se encuentra situado en la comunidad afroecuatoriana de Mascarilla, parroquia del Cantón Mira, en la provincia del Carchi, ubicada a 125 kilómetros al norte de Quito, y a unos 136 kilómetros al sur de la frontera entre Ecuador y Colombia. Mascarilla es parte de las 52 comunidades descendientes de esclavizados que desde el siglo XVII fueron introducidas por los jesuitas para trabajar en una región andina que primero se le denominó el valle de Coange y luego valle del Chota (E. Boison 2011). Hoy la zona de influencia afrodescendiente está comprendida por 9 parroquias y 5 cantones entre las provincias de Imbabura y Carchi; en ellos las comunidades han realizado un proceso de resignificación cultural y étnica y han denominado su asentamiento como Territorio Ancestral del Chota, La Concepción y Salinas (Antón 2010).

Para entender la historia de los afrodescendientes de Mascarilla es necesario examinar la presencia de los esclavizados en el Ecuador, la que debe ubicarse desde el momento del descubrimiento de las costas de Esmeraldas en 1526 (Pezzi 1996:22), o desde 1553 cuando ocurre la leyenda del naufragio de Antón, Illescas y otros esclavos en la bahía de San Mateo (Esmeraldas) ${ }^{5}$. 


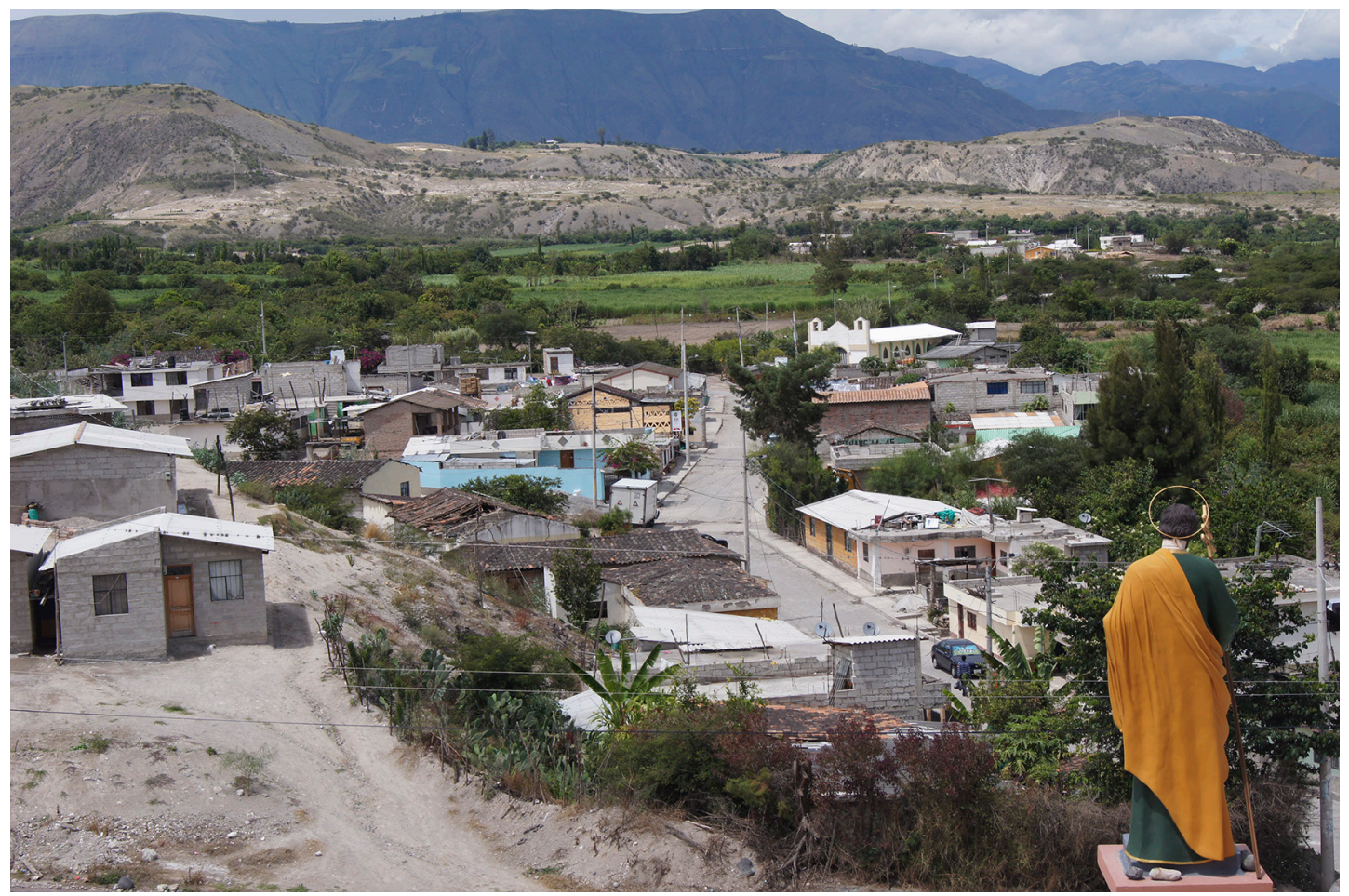

Fotografía 2. Vista parcial de la comunidad de Mascarilla, valle del Chota, Ecuador. Autor John Antón.

Luego de Esmeraldas, la presencia de los descendientes de africanos en el valle del Chota fue también significativa. Durante el siglo XVII, en el periodo de la transición de las plantaciones de coca y algodón a las haciendas azucareras, se introducen esclavizados a esta fértil región del norte ecuatoriano (Coronel 1991). Luego de la disminución de la población indígena mediante los sistemas de explotación de la mita y la encomienda, a partir de 1610 la Corona española facilita la introducción de forasteros y vagabundos que puedan trabajar en las haciendas. Entre 1680 y 1760 la Compañía de Jesús resuelve importar esclavos en gran cantidad (Kapenda 2001:117).

La importación de esclavos al valle del Chota fue intensa. Según cálculos de 1780, 13 años luego de la expulsión de los jesuitas del Ecuador ${ }^{6}$, en esta región existían 2.615 esclavos de todas las edades, de estos, 1.364 estaban destinados al trabajo pesado en las 1.037 cuadras de caña de estas haciendas (Coronel 199: 88). La trata negrera comenzó a disminuir luego de la libertad de vientres decretada en 1821 por el Congreso de la Gran Colombia, siendo abolido el sistema de esclavitud totalmente en 1852 mediante el gobierno del presidente Urbina.
De acuerdo con Costales (1964), la vida que los esclavos llevaban en las haciendas de caña de los jesuitas en el valle del Chota era miserable. Eran considerados piezas o mercancías tal como los animales, instrumentos de trabajo o bienes monetarios. Como propiedad que eran, los amos controlaban toda la vida del esclavizado, ellos decidían cuándo tenían que trabajar y descansar, cuándo debían comer, tener hijos, casarse, hacer una fiesta o realizar celebraciones como el bautismo o el matrimonio.

En el valle del Chota, como en otros centros esclavistas de la Real Audiencia de Quito, los esclavos hicieron resistencia mediante levantamientos, huidas y revueltas. En 1799 la familia de Cristóbal Trinidad y Fulgencio Congo se levantó contra sus amos en la hacienda de Carpuela. También en la hacienda La Concepción se revelaron Francisco Carrillo y Polonia Méndez. Uno de los casos más notorios de resistencia fue la querella elevada por Martina Carrillo, de la hacienda La Concepción, con el propósito de reclamar su libertad ante los tribunales de Quito (1778). Asimismo, se destacan Pedro Pascual Lucumí (1778) y Ambrosio Mondongo (1789) en Salinas (Chalá 2006). 
Ya en la vida republicana, Ecuador perteneció a la Gran Colombia. El 28 de mayo de 1821 los legisladores en el Congreso de Cúcuta aprobaron la libertad de partos a los esclavos. Contrario a lo que se piensa, la abolición legal del sistema esclavista, en lugar de permitir la autonomía y la libertad plena de los descendientes de la diáspora africana, condujo más bien a la agudización de su condición de explotación (Jaramillo 1969: 36).

Como ocurrió en toda la América Hispana con la abolición de la esclavitud, el sistema no se extinguió, más bien se modernizó y cambió de modalidad. A más de que la naciente nación debió indemnizar a los esclavistas con el sistema de manumisión, permitió que se desarrollara una nueva forma de servidumbre sustentada en el sistema del Concertaje y el Huasipungo (Ibarra 1988).

En efecto, luego de abolido el sistema esclavista, los libertos del Chota quedan sin tierra y sin alternativa distinta a continuar al servicio de su antiguo amo y dueño de las haciendas, quien pasa a emplearlos como peones con salarios de miseria e incluso arrendándoles porciones de tierras a cambio de varios días de jornal sin ninguna compensación económica. Al respecto, el historiador Jaime Espín (1996) anota:

La apertura dada con la manumisión de esclavos no significó una presencia del Estado en el espacio social, sino una dependencia del nuevo dueño con el mismo sistema de dominio de la hacienda. La subordinación de los campesinos adquiere otro carácter: el trabajo antes sancionado socialmente por una relación servil" con el patrón y dueño de sus vidas, se convierte en un trabajo contractual a cambio de un salario y del huasipungo (Espín 1996:32).

Luego de la esclavitud vino el concertaje. Este sistema de explotación fue muy severo hasta 1895 , cuando el general Eloy Alfaro impulsó la revolución liberal. Sin embargo, fue sustituido por el huasipungo, otra manera de sometimiento campesino a los hacendados vigente hasta 1964 cuando la dictadura militar decretó la reforma agraria (Espin 1993,1999). Con la instauración del concertaje y el huasipungo, los peones afrodescendientes comenzaron su proceso de campesinización, momento que marcó un nuevo episodio en su vida: la organización en torno a la defensa de la tierra que se gestó a partir de la primera mitad del siglo XX (Brassel Frank; Herrera Stalin; Michel Laforge 2008).

Según Rodríguez (1994), en la década de 1940 se inicia el proceso de fragmentación y parcelación de la hacienda terrateniente de la provincia ecuatoriana. Para la década de 1950 se inaugura el proceso de modernización de la hacienda que culmina con la primera reforma agraria de 1964 y la entrega de huasipungos a los campesinos. Pero estas transformaciones fueron producto de la presión campesina sobre las tierras de los latifundios. Desde 1940, los campesinos se organizaron en cooperativas agrícolas y en sindicatos, generando conflictos con los terratenientes. Los hacendados comenzaron a vender los terrenos para así evitar el interés de los campesinos en tomarse las parcelas (Bretón 2011).

Durante el gobierno de Galo Plaza (1948-1952) se genera en el Chota una política agraria de apoyo "a los pobladores del Mira" a partir de la parcelación del extenso latifundio de San Nicolás. Los sindicatos de campesinos en el valle del Chota se organizaron e intentaron comprar las tierras; en determinados casos, las comunidades afroecuatorianas de la sierra reclamaron violentamente por sus territorios. En la década de 1950 los campesinos de la hacienda Caldera (Cantón Bolívar) protagonizaron varios episodios de revueltas. De acuerdo con Rodríguez (1994), se desatan huelgas contra la hacienda y reclamos como "el pago de haberes y la entrega de huasipungos. Los dueños no aceptan estas exigencias y se declara un paro que dura ocho meses. Al final de este se logra la entrega de algunos huasipungos" (Rodríguez 1994:51).

Desde 1950 se desintegra la antigua hacienda, pero los conflictos agrarios se agudizan. En el valle del Chota este proceso se afianza luego de la reforma agraria de 1964. Según Naranjo:

Hasta entonces, seguía prevaleciendo en la zona la hacienda cañera en menor extensión y en manos de familias terratenientes locales tradicionales o no; su producción se destinaba principalmente al Ingenio Azucarero del Norte (IANCEM), que nace a inicios de los años 1960 por iniciativa de la Caja del Seguro (dueña a su vez de la hacienda Tababuela), y que se constituye posteriormente en la agroindustria más importante de los valles del Chota y Mira, a la que actualmente están vinculadas las 
familias pequeño y mediano productoras de la zona Naranjo (2005:90).

Luego de 1970 la hacienda cañera entra en crisis. Es desplazada por fincas que surgen "vía herencia de tierras" o por las particiones hechas de las mismas entre las familias de los antiguos trabajadores, transitando así al cultivo de productos agrícolas como el tomate, el riñón y el fréjol, mientras que las pocas haciendas que subsisten en la microrregión del Chota-Mira continúan ligadas a la agroindustria de caña para la producción de alcohol, azúcar o espárragos (Naranjo 2005: 92-95).

$\mathrm{Al}$ respecto, durante los años 60 y 70 se dio un proceso organizativo de cooperativas, sindicatos o grupos de campesinos que se movilizaban por la tierra. Muchas asociaciones desembocaron en la conformación de la Federación de Trabajadores Agrícolas del Valle del Chota FETRAVACH (1976), y la Juventud de Trabajadores del Valle (Tamayo 1996).

\section{El Trapiche de Mascarilla: la historia oral}

Las historias orales aún mantienen su vigor en estos tiempos de modernidad. La oralidad es un instrumento que relata los sucesos de la vida cotidiana, con el fin de preservar la memoria y recrear la identidad. Para Alessandro Portelli (1981) contar una historia es levantarse contra la amenaza del tiempo. De allí que, para algunas sociedades como las afroamericanas, la oralidad y la narración oral cobran importancia, ya que les permite no desconectar su presente de su historia y mantener viva su memoria colectiva e individual (Jelin 2002). De acuerdo con Odile Hoffman (2000), en el caso afrodescendiente la historia oral es consustancial al fortalecimiento de la identidad étnica y sus expresiones políticas.

Eran los comienzos del siglo XX, los tiempos de la dominación hacendataria en Ecuador (Hurtado 1993; Guerrero 1978). En el contexto del tiempo histórico del Ecuador, se terminaba la guerra liberal y, con el triunfo de la revolución alfarista, se abolía el concertaje como una práctica colonial postesclavista, pero se inauguraba otra forma de explotación servil, señorial y hacendataria: el huasipungo (Quintero y Silva, 2013). En lo que es hoy Mascarilla, los campesinos afroecuatorianos, exesclavos, se mantenían en chozas alrededor de la hacienda y del trapiche.
Mascarilla en ese entonces se configuraba territorialmente a partir del modelo de la hacienda: la casa de hacienda, el trapiche, las tierras sembradas de caña de azúcar y los huasipungueros y sus chozas con techos de paja y paredes de barro. De acuerdo con los relatos de don Asael Acosta, toda la hacienda tenía alrededor de 350 hectáreas, incluyendo lo que hoy es el pueblo de Mascarilla. Esta hacienda limitaba con otras como Pambahacienda y la hacienda San Nicolás.

La hacienda de Mascarilla tuvo varios dueños. Según don Asael: el trapiche fue en un primer momento de Jesús Jácome. Después pasó a manos de Virgilio Tamayo. Don Asael cuenta que ya en aquel entonces él trabajaba en la hacienda, siendo todavía un guambro. Más tarde la propiedad pasó a manos de Carlos Puga, a quien se le expropiaría tiempo después. Esta relación de dueños consecutivos concuerda con el relato de don Ismael Padilla, nacido en 1933, quien recuerda que su madre Martha Acosta trabajó en el trapiche como peona de la hacienda y empapeladora.

$\mathrm{Al}$ indagar las memorias de la comunidad de Mascarilla acerca de cómo han vivido la historia del trapiche, es posible que nos encontremos con relatos orales y distintas percepciones de una misma realidad. Según Portelli (1991), esto indica límites preexistentes entre el hecho real y las maneras de recordarlo. Es decir, que se presentan controversias entre la narrativa y el evento. De acuerdo con los relatos, el Trapiche de Mascarilla es símbolo de lucha y de la unión de la gente por un territorio, por la posesión colectiva de la tierra para el trabajo y el sustento, con el objetivo de terminar con la servidumbre, la explotación y la humillación.

Don Asael Acosta (74 años) es uno de los ancianos de la comunidad, quizá uno de los últimos hausipungueros que preserva la memoria colectiva del trapiche. En una tarde de sol en Mascarilla, disfrutando de una limonada helada, relata lo siguiente:

Este trapiche ya tiene muchos años en la comunidad. Cuando yo nací ya existía. Era un gran trapiche que permitía preparar la panela, la cual era la mejor, lo mismo que el aguardiente conocido como trago. Yo trabajé en esta Hacienda representando a mi mamita, la señora Asunción Martha Acosta, pues mi hermano mayor se fue al cuartel y ella sufría mucho. Ella era peona de hacienda y empapeladora de la 


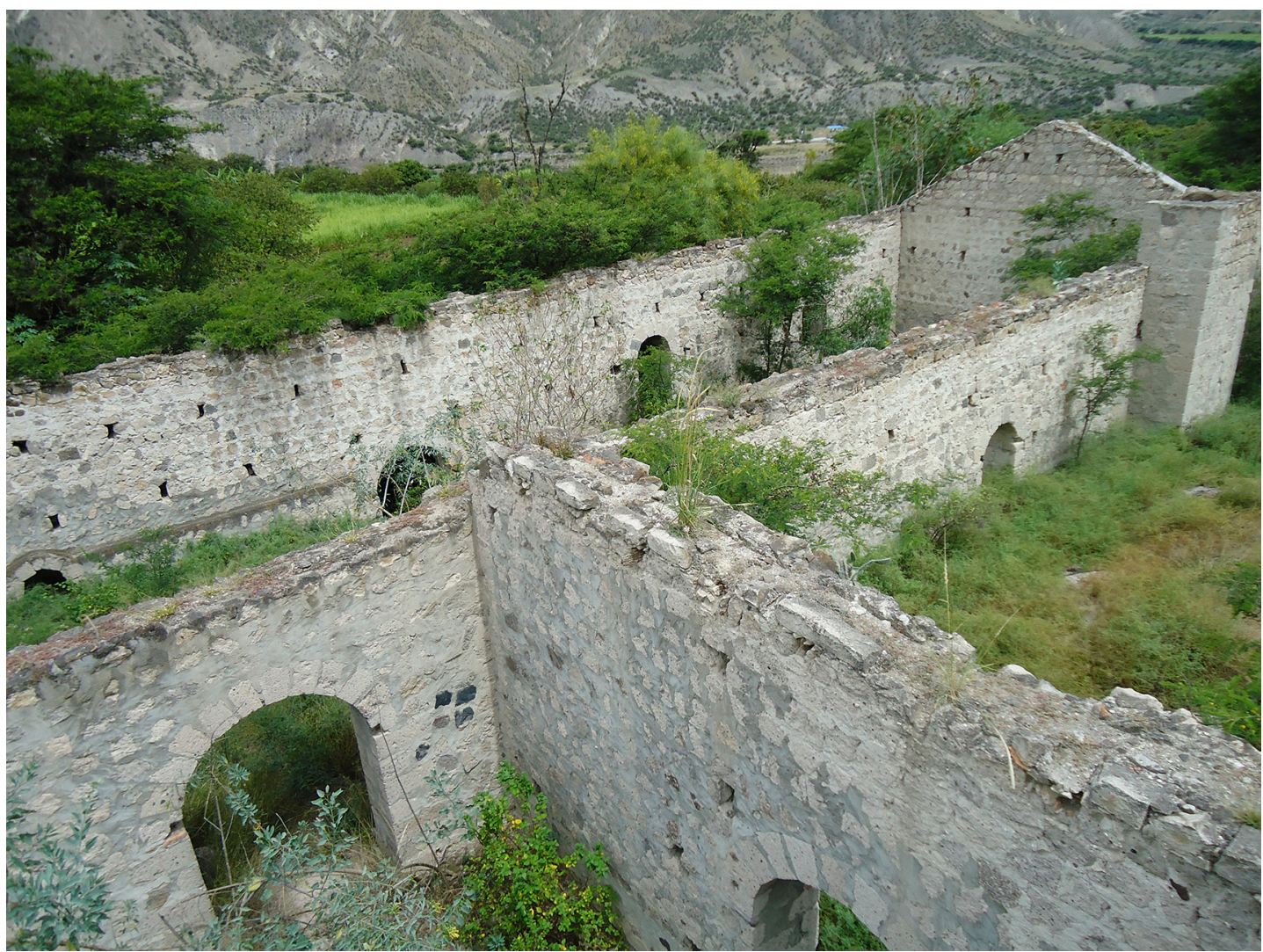

Fotografía 3. Vista parcial aérea del Trapiche de Mascarilla, valle del Chota, autor John Antón.

panela, por esta razón me tocó retirarme de la escuela de segundo grado y empezar a trabajar en las moliendas. Aquí (en el trapiche) el trabajo era muy fuerte, tocaba malanochar desde jueves a domingo. Y nos pagaban muy poco, pero trabajamos con amor. Este trapiche era muy grande. Tenía una hidráulica que permitía trabajar en dos pailas y trabajar en la noche. Hoy en día hay pocos trapiches como el que había en Mascarilla. Sin embargo, existían trapiches en Caldera, Chota Chiquito, Pimampiro y Piquiucho.

El trapiche y la hacienda fueron conquistados por los campesinos. Se trató de un largo proceso que significó la organización de la comunidad, así como la lucha, mediante la acción de mecanismos de presión y negociación.

En 1945, los relatos en la memoria de don Asael Acosta cuentan que una vez, mientras se encontraba descansando en su cama, alguien se apareció a su lado y le preguntó: “¿Por qué no le expropian el trapiche a los Puga?". Al día siguiente, don Asael llegó a la hacienda y le contó a su amigo Fabián la visión que había tenido, preguntándole: “¿por qué no le expropiamos la hacienda?", a lo que Fabián contesta: "¿con qué piedad vamos a expropiarles esa hacienda? En ese tiempo don Asael era presidente del Club Simón Bolívar de Mascarilla, una asociación de 50 jóvenes.

Don Asael era amigo del señor Rogelio Jaramillo, quien alguna vez le contó que en Ibarra se encontraban las oficinas del Instituto Ecuatoriano de Reforma Agraria (IERA) y que allí apoyaban a los que trabajaban y cultivaban las tierras. Es así que don Rogelio Jaramillo le recomendó que, junto con los miembros del Club, fueran a consultar a Ibarra respecto del proceso de apoyo para la recuperación de las tierras. En efecto, fueron a las oficinas del IERA y conversaron con el director. Le informaron que ellos estaban organizados y que no sabían cuántas hectáreas tenía la hacienda. Comienza así un proceso complejo de defensa y 
expropiación de la hacienda Mascarilla, proceso que culminó en 1966, cuando el gobierno entrega la hacienda a treinta y siete grupos familiares organizados, entre estos se destacan las familias de Asael Acosta, Aureliano Acosta, Miguel Mideros, Amado Lara, Aucimaro Minda, Hernán Folleco, Orlando Folleco, Juan Folleco, Gilberto Padilla, Salomón Acosta, Arnulfo Borja, Milton Mideros, Mauro Acosta, Norberto Minda, Georgina Mina, Piedad Borja, Berta Acosta. A cada familia le correspondieron aproximadamente tres hectáreas de tierra, las que debían trabajar para alcanzar su sustento. Su finalidad fue mantener la hacienda tal como venía. Aunque la casa y el trapiche no quedaron en manos de un particular, los campesinos se esforzaron por preservar estas adquisiciones.

Según cuenta don Aucímaro, durante el tiempo de Carlos Puga se entregaban lotes a los trabajadores para hacer sus chozas en el caserío de Mascarilla. Las chozas se establecían irregularmente en la vecina hacienda Pambahacienda. Don Aucímaro explica que en ese entonces se reunieron 45 jóvenes entre 20 y 30 años que no tenían dónde trabajar, con la exigencia de obtener la propiedad de la hacienda. Al comprar la hacienda colectivamente, según don Aucímaro, se acabó el sufrimiento de los mayores. De igual manera, recuerda que los cuarenta y cinco jóvenes arribaron un buen día a las oficinas del IERA en Quito, cuyo director ejecutivo era el señor Bagner Mantilla, para denunciar que a pesar de haber nacido en la hacienda Mascarilla, el dueño no les quería dar trabajo, además le manifestaron su deseo colectivo de comprar la hacienda.

\section{La vida en el Trapiche}

Don Alonso Mina Colorado, de 72 años, trabajó en el trapiche desde que tenía 14 años. Según su testimonio, muchas veces se quemó, pues trabajaba como hornero haciendo la panela. A él y a muchos de sus compañeros le pagaban 60 sucres. Cuenta que los Puga lo trataban bien, pero maltrataban a otras personas.

Doña Piedad María Socorro Espinoza Sánchez, de 82 años, recuerda que su esposo trabajó en el trapiche y que él llevaba un diario en donde escribía lo que sucedía allí. Este diario fue quemado cuando él se murió. Relata que los varones y las mujeres realizaban el mismo tipo de trabajos. Los hombres permanecían en las calentadoras hasta que el dulce estuviese listo. Luego lo ponían en moldes, secaban el dulce y las mujeres empapelaban los atados de dulces. Doña Piedad trabajó bajo el mando de sus patrones Julio Puga y Carlos Puga, quienes la maltrataban verbalmente. Ella comenzaba sus labores desde la madrugada hasta las 5 de la tarde, al igual que los demás trabajadores. Le pagaban muy poco y solo lo que los patrones consideraban. Mucha gente llegaba allí a pedir trabajo, a pesar de las condiciones laborales sumamente precarias. Gran parte de la población de Mascarilla trabajaba en el trapiche. Doña Piedad, por su parte, recuerda haber trabajado junto con Berta Acosta, hija de don Custodio Acosta.

Doña María Angélica Arce, de 84 años, también trabajó en el trapiche desde los 12 años. Desde las 6 de la mañana salía a limpiar, picar y arrancar el cogollo de la caña. Recuerda que su primer patrón así como el mayordomo eran "buenos", y la trataban bien. Luego, con los nuevos dueños, no les dejaban llevarse "ni un pedacito de caña para sus guaguas". Según su testimonio: "los malditos eran los Puga, sobre todo Nicanor Puga".

Doña Aurora Georgina Acosta Navarro nació el 29 de abril de 1929. Su memoria permanece fresca. Ella relata haber trabajado en el trapiche desde los 18 años. Empapelaba los dulces, limpiaba la caña en un sitio que le llamaba La Playa de Pambahacienda. Su patrón era Virgilio Tamayo, quien estuvo antes de Carlos Puga.

Don Aucímaro Espinosa tiene 60 años y también comparte sus recuerdos en el trapiche. Narra que su papá, el señor Ulpiano Espinosa, trabajó allí como hornero, su labor era la de meter el bagazo al horno para que se cocinara la miel, también trabajaba en las jornadas de molienda que eran desde el jueves en la noche hasta el sábado en la mañana. Para que su papá descansara, él y dos hermanos mayores le ayudaban a hornear.

Don Fabián Heriberto Méndez Viscarra, de 70 años, trabajó en el trapiche teniendo unos 25 años. Reemplazó a su padre (desde 1960). Le correspondía moler la caña, luego el jugo iba por un canal a las pailas hasta que se formaba la miel espesa con la que se hacían atados grandes de panela. Según él, Carlos Puga Vaca le compró todo el territorio -incluidos los trabajadores- a Virgilio Tamayo. Eran unas 370 hectáreas aproximadamente, con 22 huasipungueros, a quienes Puga les había dado unos pedacitos de tierra para que apenas sobrevivieran. Afirma que esto era la continuidad de la esclavitud, porque las largas jornadas de trabajo (desde las 5 


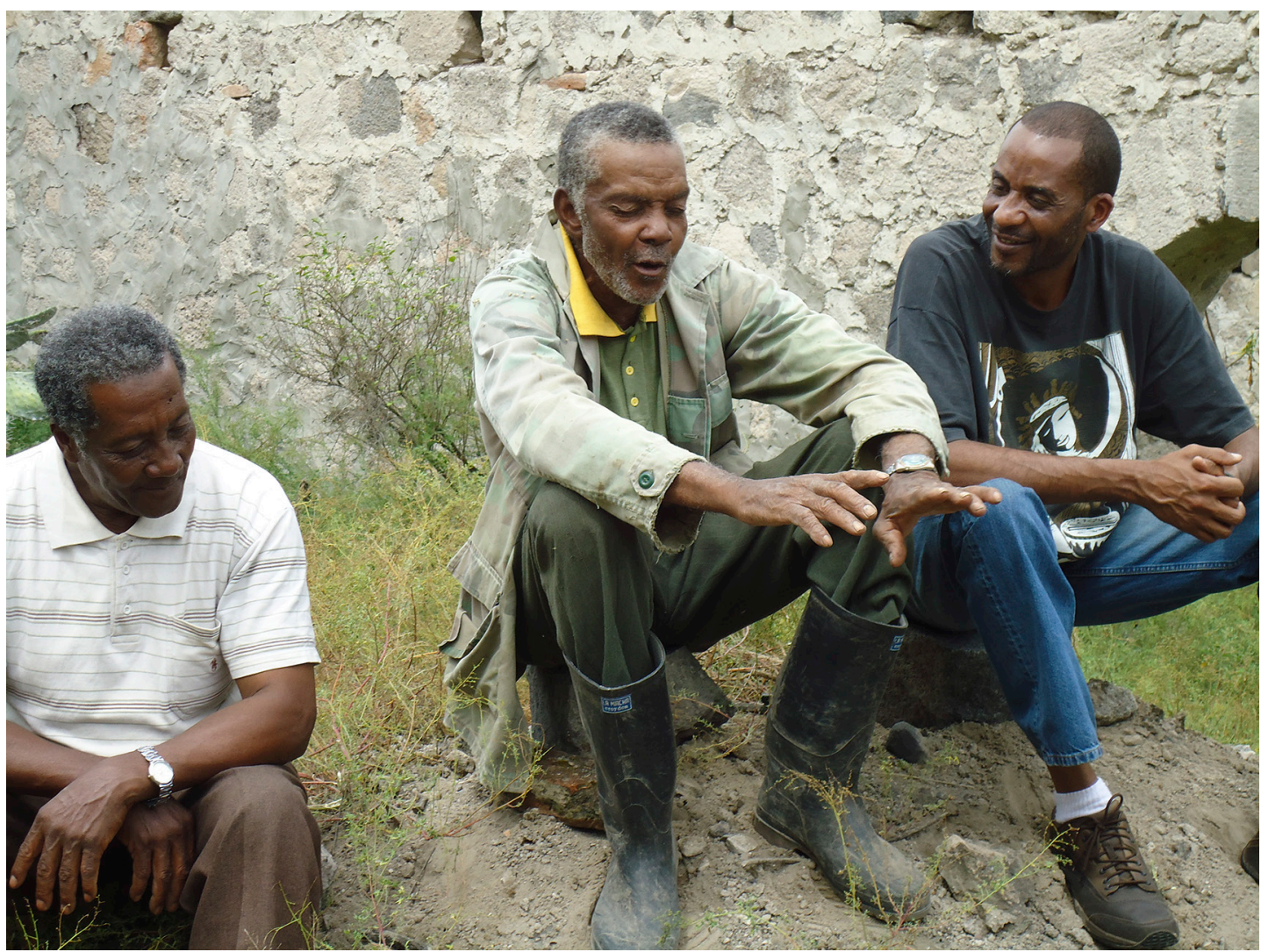

Fotografía 4. Conversando sobre el Trapiche de Mascarilla.

de la mañana hasta las 7 de la noche) no les daban tiempo de trabajar su "pedacito" de tierra. El pago era de 2,50 sucres, luego subió a 3,50. Luego de la reforma agraria culminó en 4,50 sucres. Ese dinero alcanzaba apenas para sobrevivir y para ayudarse sembraban en los terrenos yuca, camote y frejol.

Don Willson Aureliano Vinueza tiene 72 años. Recuerda que trabajó muy poco tiempo en la hacienda (desde los 9 hasta los 12 años), el resto del tiempo trabajó en compañías fuera de Mascarilla. Para él, el trabajo (en el trapiche y la hacienda) era una esclavitud. Cuenta que sus padres tenían claro que sus hijos no tenían por qué trabajar allí, ni ayudarles en su trabajo, por el que recibían una miseria como pago. A sus padres les pagaban 1,50 sucres, "ese dinero no alcanzaba ni para 3 libras de arroz y eso que en esa época el arroz era barato. Por eso, cuando el patrón se dormía, ellos sacaban su poco de miel y se llevaban a sus casas para ahí armar los atados e ir a cambiar por maíz o papas arriba a lo frío, solo así la gente se podía mantener".

\section{Las propietarias actuales del Trapiche: las GAEN}

Anita Lucía Lara, de 37 años, pertenece al Grupo de Artesanas Esperanza Negra (GAEN) propietario del trapiche. Para ella, este grupo no tiene fines de lucro y se creó con el propósito de tener un espacio donde las mujeres puedan trabajar. Lo que Anita recuerda del trapiche se refiere a cuando todavía vivía su abuelo y él solía traer pedacitos de caña ya cortados para todos sus nietos. Recuerda que cuando ella tenía 10 o 12 años el trapiche ya no funcionaba, aunque todavía estaba la rueda hidráulica que pasaba el agua por la acequia y hacía dar vuelta a la rueda.

Anita resalta que el trabajo en el trapiche era un sacrificio muy grande que hacían sus antepasados. Considera esa etapa muy dura, aunque para ella resulta necesario recordar, educando a la gente, en especial a los mismos habitantes del sector respecto de la importancia que tiene ese sitio, al ser este el 
lugar donde se forjaron los ancestros. Ella establece que el trapiche representa un patrimonio, por ello es necesario hacer un museo con ayudas audiovisuales para recordar las vivencias de los antepasados. Expresa que allí se deben poner fotografías de líderes y lideresas como "mamá Martha" con una pequeña reseña de lo que han hecho, porque "es muy importante recordar nuestra historia". En su opinión, si se logra rescatar el Trapiche de Mascarilla como un museo, las cosas van a cambiar porque la comunidad va a tener un lugar que cuente la historia y va a ser más reconocido.

\section{Conclusiones: el Trapiche de Mascarilla y la reinvención de la memoria ancestral}

En este artículo se ha argumentado en torno a la importancia del Trapiche de Mascarilla como un bien patrimonial de la cultura material afroecuatoriana, vinculado como un lugar de la memoria que reconstruye la historia de una comunidad descendiente de esclavizados africanos. Se ha presentado la propuesta de la comunidad respecto de la salvaguardia de este monumento, cuyo objetivo sería la recuperación de la memoria colectiva como parte estratégica de la revitalización de la identidad afrodescendiente en el Ecuador.

El Trapiche de Mascarilla se convierte en un lugar de la memoria para los afrodescendientes. Pero esta es una memoria especial, con el calificativo de ancestral, pues compromete la raíz de los ancestros (los "mayores"), quienes han transmitido una herencia cultural en muchas ocasiones bajo el riesgo de desaparecer. A partir de estas concepciones de recuperación de la memoria por medio de la salvaguardia del trapiche, lo ancestral más que una cuestión auténtica y originalmente antigua, corresponde a una invención con propósito ideológico. Por ello, Terence Ranger y Eric Hobsbaws (1983) hablan en sus estudios sobre África de las tradiciones inventadas, donde lo "ancestral" es entendido como una construcción cultural que una sociedad lleva a cabo en un determinado presente histórico. Desde esta visión, la memoria corresponde a un repertorio que hay que reinventar constantemente para responder a las cambiantes condiciones del mundo en que se vive.

El Trapiche de Mascarilla es un memento, un lugar vivo de la memoria, un espacio patrimonial que salvaguardado desempeñaría un rol como el de los museos. En este sentido, Elizabet Jelin (2002) sostiene que los museos son portadores de marcas de la memoria que se despliegan en un escenario político entre actores en disputa. De modo que la representación en un museo permite resolver cuestiones de inclusión y participación o, por el contrario, puede profundizar los problemas de exclusión y subordinación. Precisamente, el tema de la inclusión cultural es uno de los puntos estratégicos de la agenda política afrodescendiente, por tanto, pugnar por un espacio en el museo o en el catálogo de sitios patrimoniales materiales es conquistar un espacio en la historia de la exclusión, constituye una lucha cuyo triunfo social sería la recuperación del pasado en el presente, con perspectiva de un proyecto de nación incluyente.

Ya lo afirmaba José Chalá Cruz, un líder del movimiento social afroecuatoriano, en un taller de etnoeducación en el valle del Chota:

"nuestras comunidades deben recuperar la memoria colectiva e histórica, esto es construir nuestros discursos desde nuestras realidades y pensamientos. La pérdida de la memoria implica la pérdida de la conciencia de ser".

Este testimonio de José Chalá plantea un desafío: movilizarse en torno a la visibilización, toda vez que denuncia que la historia oficial los ha relegado a la periferia. Al respecto, Norman Whitten (1992) escribió que la identidad afroecuatoriana ha sido percibida por las élites nacionales con una marcada inferioridad, aún más que la indígena, excluida y sometida a la ideología del blanqueamiento y a pretendidas estrategias de homogeneidad mestiza nacional. Acerca de este punto, Carlos de la Torre (2002) agrega que en las reflexiones de los intelectuales respecto de la nación, los afrodescendientes han sido vistos como un problema, con dificultades para incorporarlos a la civilización. Para demostración de ello se revisan los planteamientos de intelectuales como Alfredo Espinosa Tamayo (1916), quien representa al afroecuatoriano como "parte de un mundo de la naturaleza, carente de civilización y cultura y como la raza menos apta para incorporarse a la civilización".

Igualmente, las lecturas que sobre el Trapiche de Mascarilla hacen los campesinos afroecuatorianos, por medio de los relatos orales, expresan experiencias de historia y memoria que fortalecen su identidad. Por tanto, recuperarlo como bien patrimonial se 
convierte en un mecanismo de revitalización de la identidad cultural afrodescendiente.

La propuesta que plantea este artículo tiene que ver con la necesidad de que el Estado y la academia impulsen propuestas de rescate del Trapiche de Mascarilla como un bien patrimonial, utilizando técnicas de recuperación de bienes históricos como aquellas que se han referenciado como arqueología histórica afrodescendiente.

En Ecuador la arqueología histórica afrodescendiente podría explorar áreas de asentamiento ancestral de esclavizados en las provincias de Esmeraldas, Imbabura y Carchi, lugares donde se tiene una presencia significativa de estas comunidades. En estos territorios podrían identificarse escenarios arqueológicos históricos como: palenques, minas, haciendas, poblados antiguos, cementerios y ruinas históricas (Trapiche de Mascarilla). Los resultados de este trabajo servirán para comenzar una recolección sistemática de los valores del patrimonio material de cultura afroecuatoriana en el país, la misma que requiere con urgencia un plan de identificación, preservación y salvaguardia.

Luego de explorar la literatura pertinente al tema en el país, se podría afirmar que para Ecuador la arqueología histórica de la diáspora africana en las Américas ha sido comenzada por Daniela Balanzátegui (2017), quien realizó un trabajo titulado Archaeology of the Afro-Ecuadorians in La Concepción, Ancestral Territory of the ChotaMira Valley (Carchi-Ecuador), como requisito para su doctorado en la Universidad de Simón Fraser (Canadá).

Para Balanzátegui (2017), la arqueología histórica de la diáspora africana en las Américas insta a la interdisciplinariedad de enfoques colaborativos e interculturales para arrojar luz respecto de cómo la cultura material refleja las condiciones de esclavitud y racialización, pero también el proceso de resistencia y reparación histórica de las comunidades. Su investigación intenta arrojar luz en los procesos de construcción cultural de los africanos esclavizados y sus descendientes en el valle del Chota, entre el siglo XVII hasta el siglo XXI, centrándose principalmente en los restos de la cultura material encontrados en la hacienda jesuita de la Concepción, donde se encontraron cerámicas asociadas al consumo doméstico de los esclavizados, en lo que fue en aquel entonces el cementerio de los esclavizados. Además de ser pionero en esta materia, el trabajo de Balanzátegui combina el análisis arqueológico de la cultura material asociada con los afrodescendientes en contextos domésticos, con la investigación de archivos e investigación etnográfica para reconstruir y comparar patrones de consumo, interacción étnica y significado patrimonial de los afroecuatorianos.

Finalmente, la recuperación de la memoria colectiva e histórica del trapiche por medio de una política de salvaguardia patrimonial sería un asunto estratégico de revitalización de la identidad afrodescendiente del Ecuador. En un futuro, cuando el INPC y el gobierno decida construir allí el Museo de la Memoria o de la Historia de la Diáspora Africana en las Américas, los afrodescendientes harán del lugar un vehículo para potenciar el discurso político alrededor de los derechos culturales, de su importancia como pueblo en la construcción del Estado Nacional, y de cómo se puede cumplir con el propósito constitucional de hacer del Ecuador una nación plurinacional e intercultural, según el artículo 1 de la Constitución de Montecristi.

\section{Referencias Citadas}

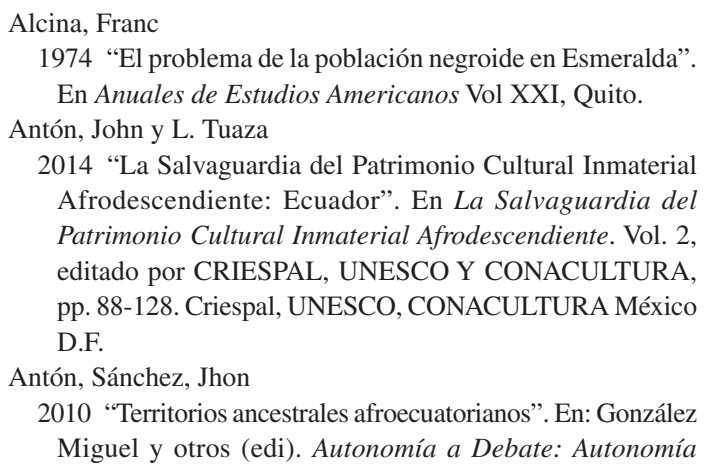

indígena y estado plurinacional en América Latina. FlacsoGTZ. Quito, pp. 219-259.

Arcila, Graciliano

1955 "Anotaciones sobre la ubicación de Santa María la Antigua del Darien”. En Boletín del Instituto de Antropología. 1 (3): 257-287. Bogotá.

Balanzátegui Moreno, Daniela

2017 Archaeology of the Afro-Ecuadorians in La Concepción, Ancestral Territory of the Chota-Mira Valley (CarchiEcuador). Tesis Doctoral de la Universidad Simón Fraser. Burnaby, British Columbia, Canadá.

Barnet, Miguel

2006 "La promoción y difusión del patrimonio inmaterial de la humanidad: un enfoque antropológico". En VII Encuentro 
para la promoción y difusión del patrimonio inmaterial de países iberoaméricanos, editado por M. Giraldo, pp. 45-59. Dupligráficas. Bogotá.

Bastides, Roger

1967 Las Américas Negras: Las civilizaciones africanas en el Nuevo Mundo. Alianza Editorial, Madrid.

Binford, L.

(1983) 2009 En busca del Pasado. Descifrando el registro arqueológico. Crítica, Barcelona.

Brassel Frank, Herrera Stalin y Michel Laforge (editores)

2008 ¿Reforma Agraria en Ecuador?: viejos temas, nuevos argumentos. SIPAE. 248 p.

Bretón, Víctor

2011 "Las dimensiones poliédricas del crepúsculo de las haciendas norandinas". En: Pablo Palenzuela y Alessandra Olivi (coordinadores), Etnicidad y desarrollo en los Andes. Universidad de Sevilla. Sevilla.

Cabello de Balboa

(1583) 1945 Verdadera descripción y relación larga de la provincia y tierra de las Esmeraldas. Volumen 1. Editorial Ecuatoriana, Quito.

Chalá, José

2006 Chota profundo: Antropología de los afrochoteños. Ed. Abya-Yala, Quito.

Chiriboga, Argentina; Savoia, Rafael; Gomezjurado, Javier (comps.).

1999 El negro en la historia del Ecuador: esclavitud en las regiones andina y amazónica. Quito: Centro Cultural Afroecuatoriano.

Coronel Feijoo, R.

(1991) 2015 El valle sangriento: de la coca indígena a la hacienda jesuita en el Chota, 1580-1700. Segunda edición. Corporación Editora Nacional, Quito.

Costales, Alfredo y Piedad Peña Herrera

1964 Historia social del Ecuador: El Concertaje de Indios y la Manumisión de Esclavos. Casa de la Cultura Ecuatoriana. Quito.

De la Torre, Carlos

2002 Afroquiteños, ciudadanía y racismo. Centro Andino de Acción Popular CAAP, Quito.

Duque, Luis

(1955) 2005 Colombia: monumentos históricos y arqueológicos. Vol. 163 de Biblioteca de Historia Nacional. $2^{\mathrm{a}}$ ed. de Academia Colombiana de Historia, Bogotá.

Eric, Hobsbawm y Terence Ranger (eds.)

2005 La invención de la tradición. Crítica. Barcelona.

Espin, Jaime

1993 Campesinos del Mira y el Chanchán. Ed. Abya YalaPUCE, Quito.

Espín Díaz, Jaime

1999 "Estrategias campesinas de sobrevivencia y de reproducción social de la población negra del Valle de Chota, Ecuador". En libro: Estrategia de seguridad alimentaria en América Latina y África. CLACSO, Consejo Latinoamericano de Ciencias Sociales, Buenos Aires, Argentina.

Espinosa, Alfredo

(1916) 1979 Psicología y sociología del pueblo ecuatoriano. Corporación Editora Nacional y Banco Central del Ecuador. Quito.

Estupiñán Tello, J.

1977 Historia de Esmeraldas. Editora Gregorio, Portoviejo.
Feijoo, Rosario

1991 El valle sangriento 1580-1700. Abya Yala-FLACSO. Quito.

Franco, José Luciano

1975 La diáspora africana en el nuevo mundo. Editorial de Ciencias Sociales, La Habana.

Geertz, Clifford

[1973] 1987 La interpretación de las culturas. Gedisa, Barcelona.

Guerrero, Andrés

1978 Ensayo sobre la acumulación originaria en el Ecuador: Hacendados cacaoteros, banqueros exportadores y comerciantes en Guayaquil (1890-1910). CLACSO, Quito.

Herskovits, Merville

1958 (1941) The Myth of the Negro Past. Beacon Press, Boston.

Hoffamn, Odille

2000 "La movilización identitaria y el recurso de la memoria (Nariño Pacífico Colombiano)". En Memoria Hegemónica y Memorias disidentes. Editado por Gnecco y Zambrano. ICANH, Bogotá.

Hurtado, Osvaldo

1993 Poder político en el Ecuador. Letraviva-Planeta. Quito.

Ibarra, Hernán

1988 “Concertaje, jornalero y haciendas (1850-1920)". En: Escobar Santiago (coordinador). Población, Migración y empleo en el Ecuador. Quito. Ildis, pp. 103-147.

Gilroy, Paul

2014 Atlántico negro: modernidad y doble conciencia. Akal. Madrid.

Jaramillo, Uribe J.

1969 Ensayo sobre la historia social colombiana. Universidad Nacional de Colombia. Bogotá.

Jelin, Elizabeth

2002 Los trabajos de la memoria. Siglo XXI, Madrid.

Jurado Noboa, Fernando

1990 Esclavitud en la costa Pacífica: Iscuandé, Tumaco, Barbacoas y Esmeraldas: siglos XVI al XIX. Centro Afroecuatoriano. Quito.

Kapenda, Jean

2001 Diccionario lingala-español. Breve historia y origen africano del negro ecuatoriano. UNESCO. Quito.

Kuper, Adam

2000 "La ilusión de las culturas". En Memoria, editado por Marka-Instituto de Historia y Antropología Andinas, Quito.

López, Francisco

2002 La tumba de María Isaacs: génesis y desarrollo de una leyenda vallecaucana. Ministerio de Cultura. Bogotá.

Méndez, M.

1985 Arqueología de un sitio transicional en el Valle de Popayán: La Balsa, Cajibio, Cauca. Editorial López.

Mintz, Sidney y Price, Richard

2012 El origen de la cultura africano-americana: Una perspectiva antropológica. 1976 (2012). Universidad Autónoma de México.

Moreno F. Manuel (relator)

1987 África en América Latina. UNESCO, Siglo XX, París.

Naranjo, Marcelo (coordinador)

2005 La cultura popular en el Ecuador. Tomo XII Carchi. Centro Interamericano de Artesanías y Artes Populares CIDAP. Cuenca. 
Moreno Fraginalis, Manuel

1977 “Aportes Culturales y Deculturación”. En: Moreno Fraginalis Manuel (relator). África en América Latina. Siglo XXI Editores y UNESCO. México.

Noboa, F.

1990 Esclavitud en la Costa Pacífica: Iscuandé Barbacoas, Tumaco y Esmeraldas: Siglos XVI al XIX. Abya-Yala, Quito.

Ortiz, Fernando 1906 Los negros brujos (apuntes para un estudio de etnología criminal). Librería de Fernando Fe, Madrid.

Pezzy, Juan Pablo

1996 "Aportes hacia la consolidación de la identidad cultural del negro esmeraldeño". En Identidad en Construcción, editado por Pezzy, Chávez y Minda. Abya Yala. Quito.

Portelli, Alessandro

1981 "El Tiempo de mi vida: las funciones del tiempo en la historia oral". En International Journal of Oral History. Vol. 2 Número 3 noviembre de 1981, pp. 162-180. Traducción de Victoria Schussheim.

Portelli, Alessandro

1991 The Death of Luiggi Trastulli: Memory and the Evenst. In the Death of Luiggi Trastulli and the Other Stories. Form and Meaning in Oral History. State University of Wisconsin Press. New York.

Quintero, Rafael y Charvet, Ericka

2013 Ecuador una nación en Ciernes. Tomo 1. Abya Yala. Quinta edición. Quito.

Ramos, Mariano y Hernández de Lara, Odlanyer (editores)

2011 Arqueología Histórica en América Latina, perspectivas desde Argentina y Cuba. Universidad Nacional de Luja. Buenos Aires.

Ramos, Artur

1937 As Culturas Negras no Novo Mundo. Civilização Brasileira: Rio de Janeiro.

Rivas, P. y Altez, Y.

2015 "Avances en Arqueología Afrovenezolana: el proyecto antropología de la parroquia Caruao". En Revista de Arqueología Pública, 9, pp. 36-59.

Rodríguez, Lourdes

1994 Tenencia de la tierra en los valles del Chota y de Salinas. FEPP. Quito.

Rosaldo, Renato

[1993] 2000 Cultura y verdad. Abya-Yala, Quito.

Rosaldo, Renato

1997 "Ciudadanía cultural y minorías latinas en Estados Unidos". En Culturas políticas a fin de siglo, editado por J. Pablos, pp. 242-264. FLACSO México. Mexico D.F.

Rodriguez, Nina

1935 O Animismo Fetichista dos Negros Bahianos. Civilização Brasileira, Rio de Janeiro.

Rueda, R.

2001 Zambaje y autonomía. Historia de la gente negra de la provincia de esmeraldas, siglos XVI-XVIII, Colección Marejada, $N^{\circ}$ 1, Municipalidad de Esmeraldas/Tehis/ AbyaYala, Quito.
Savoia, Rafael (coord.)

1988 Actas del primer congreso de historia del negro en el Ecuador y sur de Colombia. Centro Cultural Afroecuatoriano. Quito.

(Coor.) 1998 El Negro en la Historia de Ecuador y del Sur de Colombia. Ed. Centro Cultural Afroecuatoriano. Quito. 1990 Aportes para el Conocimiento de las Raíces en América Latina. Ed. Centro Cultural Afroecuatoriano, Quito.

1992 Raíces Africanas en la Nacionalidad Ecuatoriana-500 Años. Ed. Centro Cultural Afroecuatoriano, Quito.

Saco, José Antonio

1933 Historia de la esclavitud de la raza africana en el Nuevo Mundo y en especial en los países americano hispánicos. Prólogo de Fernando Ortiz, Cultural S.A., La Habana.

Schwegler, A.

1992 "Hacia una arqueología afrocolombiana; restos de tradiciones religiosas bantues en una comunidad negrocolombiana". En América Negra. Número (4): 35-84. Universidad Javeriana, Bogotá.

Suaza, María Angélica

1993 Arqueología en Palenque de San Basilio. Tesis de Antropología. Facultad de Ciencias Humanas. U. Nacional, Bogotá.

Tamayo, Eduardo

1996 Movimientos sociales: la riqueza de la diversidad. Agencia Latinoamericana de Información, Quito.

Tardieu, Jean Pierre

2006 Los Negros en la Real Audiencia de Quito. Abya Yala, Quito.

Taylor, S.J. y R. Bogdan

[1984] 1987 Introducción a los métodos cualitativos de investigación. Paidós, Barcelona.

Therrien, Monika

1996 "Sociedad y cultura material de la Nueva Granada. ¿Preferencias o Referencias? Aportes de la arqueología histórica en Colombia". En Revista Colombiana de Antropología (Bogotá), 33 (1996-1997): 5-51.

UNESCO

2003 Convención para la Salvaguardia del Patrimonio Cultural Inmaterial de la UNESCO. Paris.

Uribe, Jaramillo

1969 "La controversia jurídica y filosófica librada en la Nueva Granada en torno a la liberación de los esclavos y la importancia económica social de la esclavitud en el siglo XIX”. En Anuario Colombiano de Historia Social y de la Cultura. Número 4, Bogotá.

Whitten, Norman

1992 Pioneros negros: La cultura afro-latinoamericana del Ecuador y de Colombia. Centro Cultural Afroecuatoriano, Quito.

Zapata, Manuel

1997 La rebelión de los genes: el mestizaje americano en la sociedad futura. Colección Narrativa. Altamir Ediciones. Bogotá.
1 La etnografía se define como la forma del análisis antropológico de crear conocimiento, más que una técnica microscópica que le permite al etnógrafo la observación participante en el campo, donde se describen y se interpretan los contextos culturales en que se desenvuelven los actores, corresponde a un tipo de esfuerzo intelectual, una especulación elaborada de descripción densa. Clifford Geertz (1987:27) 
2 Dentro de los objetos culturales que alcanzan el carácter de patrimonialidad se presentan los siguientes elementos, según la UNESCO: ciudades históricas, sitios naturales con valor religioso para algunas culturas; paisajes culturales; museos; patrimonio cultural móvil (pinturas, esculturas, grabados, entre otros); artesanías; patrimonio documental y digital; patrimonio cinematográfico; tradiciones orales; idiomas; eventos festivos; ritos y creencias; música y canciones; artes escénicas (danzas, representaciones); medicina tradicional; tradiciones culinarias; deportes y juegos tradicionales, entre otros.

3 La Convención para la Salvaguardia del Patrimonio Cultural Inmaterial de la UNESCO (2003), en su artículo 2, numeral 1 define al patrimonio cultural inmaterial como: "Los usos, representaciones, expresiones, conocimientos y técnicas -junto con los instrumentos, objetos, artefactos y espacios culturales que les son inherentes- que las comunidades, los grupos y en algunos casos los individuos reconozcan como parte integrante de su patrimonio cultural".

4 Como referencia se puede consultar Alejandro Richard y Cristian Lallami (2017), Johana Caterina Mantilla Oliveros (2016); Lucio Menezes Ferreria, Paulo Funari, Eliz Meza y Aluisio Gomes (2016).

$5 \quad$ Ver Cabello de Balboa (1583-1945), Tardieu (2006), Rocio Noboa (2001). Otros autores destacados sobre la esclavitud en Ecuador son: Rafael Savoia (1988, 1990, 1992, 1999), Fernando Jurado Novoa (1990), Julio Estupiñán Tello (1977), José Alcina Franch (1974), Juan Pablo Pezzy (1996) y Jean Kapenda (2001), entre otros.

6 Los jesuitas fueron expulsados en 1776. Con su retiro, los grandes complejos cañeros que estaban bajo su propiedad se transformaron en pequeños complejos, los que pasaron a manos de la orden de los Dominicos y terratenientes particulares (Coronel 1991). 